\title{
Zoom in at African country level: potential climate induced changes in areas of suitability for survival of malaria vectors
}

\author{
Henri EZ Tonnang ${ }^{1 *}$, David P Tchouassi ${ }^{1}$, Henry S Juarez ${ }^{2}$, Lilian K Igweta ${ }^{1}$ and Rousseau F Djouaka ${ }^{3}$
}

\begin{abstract}
Background: Predicting anopheles vectors' population densities and boundary shifts is crucial in preparing for malaria risks and unanticipated outbreaks. Although shifts in the distribution and boundaries of the major malaria vectors (Anopheles gambiae s.s. and An. arabiensis) across Africa have been predicted, quantified areas of absolute change in zone of suitability for their survival have not been defined. In this study, we have quantified areas of absolute change conducive for the establishment and survival of these vectors, per African country, under two climate change scenarios and based on our findings, highlight practical measures for effective malaria control in the face of changing climatic patterns.

Methods: We developed a model using CLIMEX simulation platform to estimate the potential geographical distribution and seasonal abundance of these malaria vectors in relation to climatic factors (temperature, rainfall and relative humidity). The model yielded an eco-climatic index (EI) describing the total favourable geographical locations for the species. The EI values were classified and exported to a GIS package. Using ArcGIS, the El shape points were clipped to the extent of Africa and then converted to a raster layer using Inverse Distance Weighted (IDW) interpolation method. Generated maps were then transformed into polygon-based geo-referenced data set and their areas computed and expressed in square kilometers $\left(\mathrm{km}^{2}\right)$.

Results: Five classes of El were derived indicating the level of survivorship of these malaria vectors. The proportion of areas increasing or decreasing in level of survival of these malaria vectors will be more pronounced in eastern and southern African countries than those in western Africa. Angola, Ethiopia, Kenya, Mozambique, Tanzania, South Africa and Zambia appear most likely to be affected in terms of absolute change of malaria vectors suitability zones under the selected climate change scenarios.
\end{abstract}

Conclusion: The potential shifts of these malaria vectors have implications for human exposure to malaria, as recrudescence of the disease is likely to be recorded in several new areas and regions. Therefore, the need to develop, compile and share malaria preventive measures, which can be adapted to different climatic scenarios, remains crucial.

Keywords: Climate change, Eco-climatic index, African countries, Anopheles gambiae s.5, Anopheles arabiensis

\section{Background}

Efforts have been made to predict and map the potential redistribution of malaria vectors and consequently malaria transmission risk especially in the context of climate change. Such malaria risk projections invaluably may provide policy-makers with the opportunity to

\footnotetext{
* Correspondence: htonnang@icipe.org

'International Centre of Insect Physiology and Ecology (icipe), Nairobi, Kenya Full list of author information is available at the end of the article
}

initiate activities for identifying vulnerable communities in a timely manner and to develop effective strategies to curtail and prevent malaria outbreaks [1,2]. Diverse models have been used in projection studies thereby producing different malaria risk projections and corresponding shifts in future distribution and variability of malaria transmission. Most models have however, focused on key climate-based parameters such as temperature, rainfall and relative humidity as these influence the breeding, emergence and 
abundance of Anopheles vectors and parasite development, which is correlated with increased biting and transmission of malaria [3-5].

Peterson [6] applied ecological niche model using Genetic Algorithm for Rule-set Prediction (GARP) [7] and predicted the potential distributional shift from west to east and west to south of Africa for An. gambiae s.s. and An. arabiensis, respectively. Within the same context [8] it has been suggested however, that Anopheles distribution range shifts are more likely to occur than range expansions. Moreover, several studies have suggested a high probability of distributional change of current regions where malaria vectors specially occur and may potentially occur in the future with climate change [3,6-14].

Shifts in malaria transmission risk have mainly been projected on a global or continental scale with little efforts within regional or local scales (i.e., country-specific) especially in malaria disease endemic countries of Africa. Projection of future malaria risks taking into account local climatic conditions has been emphasized [15-17]. Studies of climate-malaria relationships within local scales are likely to be more useful for public health officials than broad, global-scale studies. Specifically, finer-scale analyses facilitate incorporation of local features and characteristics and may provide a greater opportunity for intervention and response, given that public health programs are typically applied at the regional or local level $[18,19]$.

In an earlier study [14], we used the software, CLIMEX, to calibrate the current and future distributions of key malaria vectors in Africa. Using this tool, the potential geographical distribution and seasonal abundance of the species in relation to climatic factors such as temperature, rainfall and relative humidity were estimated. As such, boundary shifts of the major Africa malaria vectors, Anopheles gambiae s.s. (herein referred to as $A n$. gambiae) and $A n$. arabiensis were predicted southward and eastward of Africa, respectively. Malaria vector control activities appear to be country specific in Africa and continental information as presented in Tonnang et al. [14] may either be neglected or not be applicable to every country, hence a country level projection required. Climate change potential inducing shifts of these vectors may have negative impacts for human exposure to malaria, as recrudescence of the disease is likely to be recorded in several new areas within a country. It is necessary to project how each country's territory will be affected as a prerequisite to develop, compile and share malaria preventive measures, which can be adapted to different climatic scenarios. While acknowledging the impacts of climate change on the future distribution of these malaria vectors with consequent shifts in their overall ranges, the present study sought to quantify the areas of absolute change per country in Africa beyond the already projected shifts for these species.

\section{Methods}

\section{Climate and malaria vectors data sets}

The climate data used for spatial simulations (current scenario) were obtained from the Climatic Research Unit (CRU) in Norwich UK available at http://www.cru.uea.ac. uk/. The distributional records for An. gambiae and $A n$. arabiensis used in this study were obtained from Mapping Malaria Risk in Africa (MARA) collaboration (http://www. mara.org.za/) repository of information [20]. This database contains 2,535 geo-referenced records of malaria vectors of Africa. Additional geo-reference information on malaria vectors was sourced from recent publications [21,22].

\section{Climate change projections}

For predicting the future potential distributions of species, CLIMEX platform incorporates the IPCC climate change scenarios. It is projected that globally average surface temperature is to increase by 1.4 to $5.8^{\circ} \mathrm{C}$ and a considerable change in the pattern of rainfall will occur by the year $2100[23,24]$. Within the specified framework two projected scenarios were considered as described below:

- Scenario 1: A rise of $2^{\circ} \mathrm{C}$ Africa wide temperature and 10\% increase of rainfall from March 2 -September 30 and $10 \%$ decrease in the rest of the year.

- Scenario 2: A rise of $0.1^{\circ} \mathrm{C}$ in the whole year maximum and minimum temperatures per degree of latitude, and a 10\% increase of rainfall from March 2-September 30 and $10 \%$ decrease in the rest of the year.

\section{Model development}

The simulation that yielded the eco-climatic index $(E I)$ was conducted inductively with CLIMEX platform [23]. CLIMEX makes use of the species responses to a series of stress indices (cold, hot, dry and wet) that define the species' particular environmental limits for a sustained growth and development of the population [23]. These stress indices were linearly combined to the species' growth indices to yield an EI that describes the total favourability of geographic locations for the species [14,23]. In calibrating the malaria vectors models, the "compare locations" function was run. This function links the EI to the "match climate" function that compares the meteorological data from different places, with no reference to the preferences of An. gambiae and An. arabiensis, respectively, [14].

The malaria vector distribution shape points [14] were obtained with the following procedure: Firstly, best fitted CLIMEX parameters obtained through multiple run of the "compare location" function were used for mapping the Anopheles species under current scenario. Secondly, the "compare location" function was once again run with the best-matched CLIMEX parameters and the EI for the An. gambiae and An. arabiensis were estimated under the chosen projected scenarios. The results were then 
transferred to Arc-GIS v. 9.2 (ESRI) package in order to facilitate the organization, manipulation, visualization, geospatial analysis and absolute area computations.

\section{Evaluating and quantifying the absolute range change of} An. gambiae and An. arabiensis

The CLIMEX parameters values were identical to the original model calibrated and validated for An. gambiae and An. arabiensis by Tonnang et al. [14]. The eco-climatic index $(E I)$ represented in form of maps was also similar to the results published in Tonnang et al. [14]. With ArcGIS v. 9.2 (ESRI) the shape point's outputs from CLIMEX for all scenarios (current $E I$ and projected $E I$ for scenarios 1 and 2) were clipped to the extent of Africa. Then, each point file was converted to a raster layer using Inverse
Distance Weighted (IDW) interpolation method [25] with a cell size of 3 minutes in both longitude and latitude. The maps were reclassified (Figure 1) and used as the foundation for this study. Reclassification consisted of taking input cell values and replacing them with new output cell values. It was used to simplify the interpretation of raster data by changing a single value to a new value, or grouping ranges of values into single values. The operations merely repackage existing information on a single map. The reclassified maps were converted into a polygonbased geo-referenced data set for computing areas in square kilometers $\left(\mathrm{km}^{2}\right)$ for the polygons. From the total polygon areas belonging to the same country, individual area was estimated. To estimate per country the absolute change of suitability, the difference in area between the

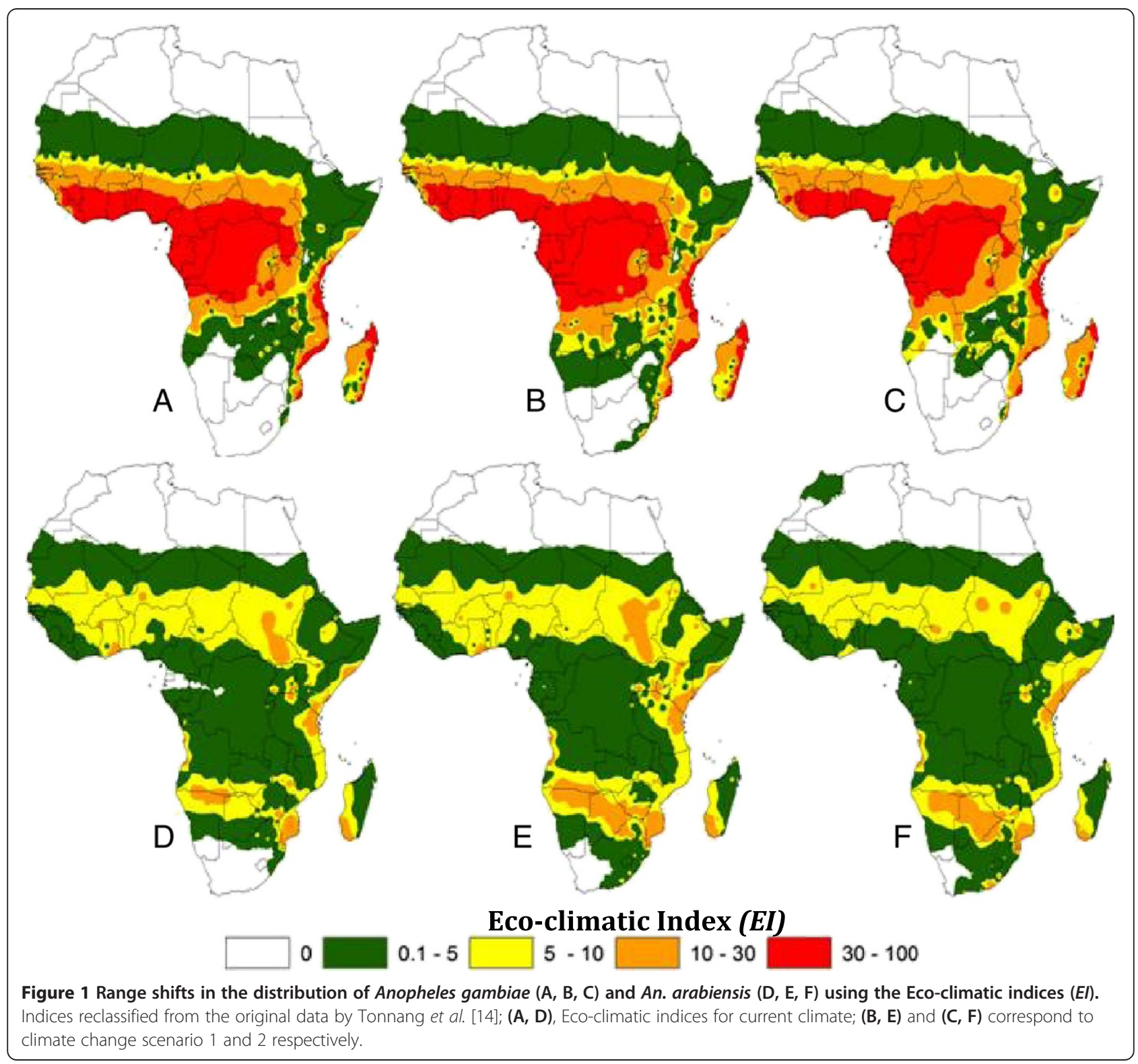


values of $E I$ for each projected scenario and the current scenario was performed for An. gambiae and An. arabiensis. Further, the percentage of range shift per country was calculated by dividing the area of absolute change over the total area of vector distribution for each country obtained from the current scenario.

\section{Results}

Regions where the Eco-climatic index (EI) equals 100 indicate climate conditions where a certain proportion of the malaria vectors population is expected to survive throughout the year, representing the regions where the likelihood of establishment is highest. In zones where the $E I$ deviates from the maximum number of 100, the likelihood of longterm survival is reduced. Based on this concept as well as referring to the actual known distributions of the species under investigation [11]; 5 classes of $E I$ were considered as shown in Figure 2: Class $1(E I=0)$ indicates that the location is not suitable for the species. Class $2(E I \leq 5)$ represents zones with very little suitability for the survival of malaria vectors. Class $3(E I=(5-10))$ indicates areas with sequential risk of establishment of the malaria vectors. Class $4(E I=(10-30))$ indicates areas with high risk of permanent establishment of malaria vector. In Class 5 $(E I>30)$ the likelihood of long-term survival of An. gambiae and $A n$. arabiensis is very high. Under projected scenarios 1 and 2, and for both malaria vectors, a country belonging to any class with the area equals to 0 is a territory with no range shift (Tables 1, 2, 3, 4). A negative value of an area signifies that a reduction of the area size will occur, whereas a positive value indicates an increment.

For An. gambiae, and with the two projected scenarios, Classes 1 and 2 display similar trend of the results with good number of the countries having either, 0 or negative area (Tables 1 and 2). In Class 1, a possible loss in area of $1,678,200 \mathrm{~km}^{2}$ (Table 1) and 463,059 $\mathrm{km}^{2}$ (Table 2) for projected scenarios 1 and 2 are predicted, respectively. Class 2 showed an analogous tendency with an estimated reduction in area of $150,534 \mathrm{~km}^{2}$ (Table 1) and 609,744 (Table 2) under succeeding scenarios. These losses of area in the classes express the reduction in zones of little and no suitability for the species. In contrast, a possible increment of $698,477 \mathrm{~km}^{2}, 378,946 \mathrm{~km}^{2}, 751,311 \mathrm{~km}^{2}$ (Table 1) is predicted under scenario 1 for Classes 3,4 and 5, respectively. Under scenario 2, a similar tendency occurs in Class $3\left(685,060 \mathrm{~km}^{2}\right)$ and Class $4\left(1,238,829 \mathrm{~km}^{2}\right)$. An

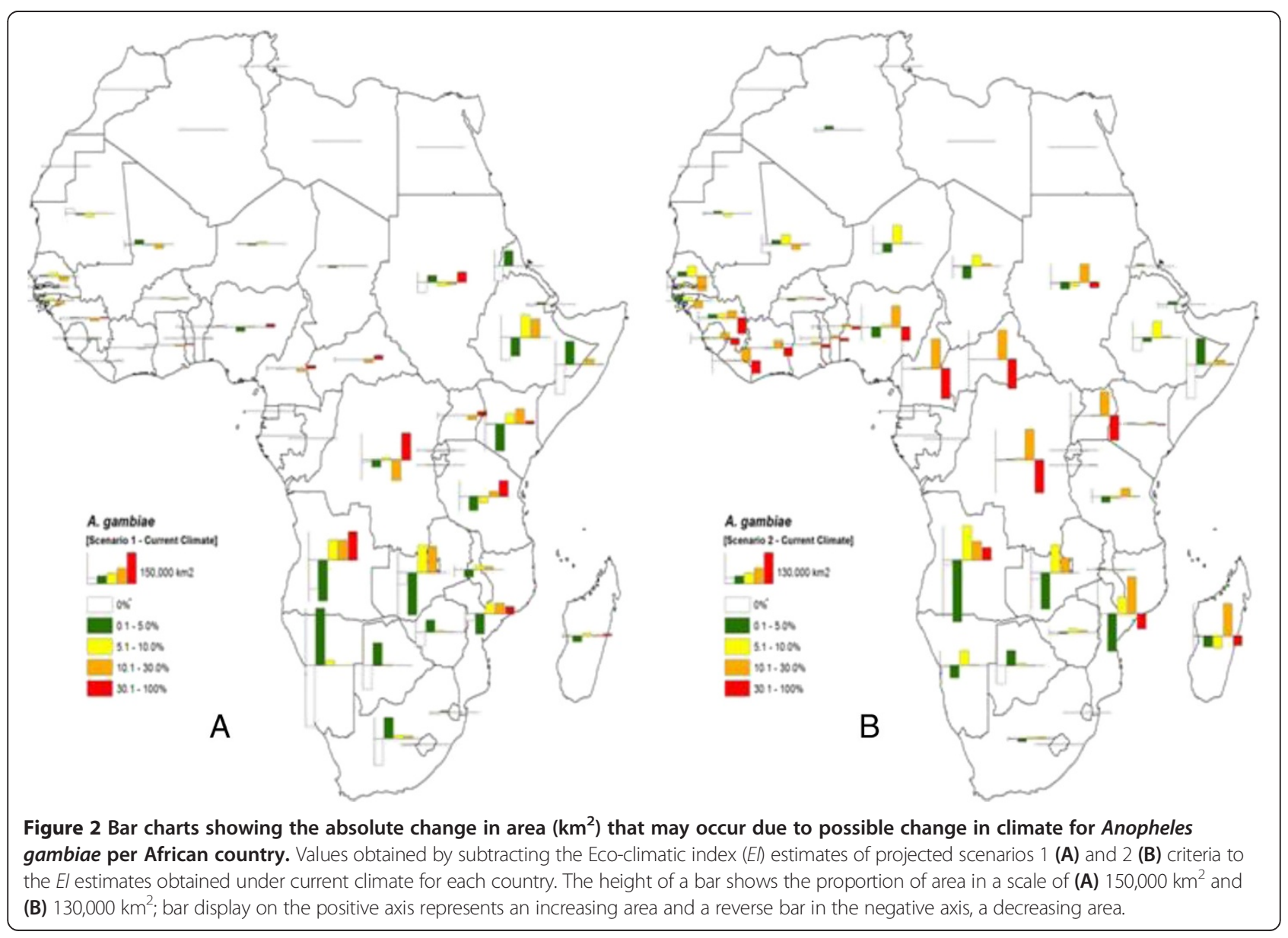


Table 1 Absolute change in areas $\left(\mathrm{km}^{2}\right)$ for An. gambiae per country of Africa under scenario 1

\begin{tabular}{|c|c|c|c|c|c|c|c|c|c|c|}
\hline \multirow[t]{2}{*}{ Countries } & \multicolumn{2}{|c|}{$E I=0$} & \multicolumn{2}{|c|}{$E I=(0.1-5)$} & \multicolumn{2}{|c|}{$E I=(5-10)$} & \multicolumn{2}{|c|}{$E I=(10-30)$} & \multicolumn{2}{|c|}{$E I=(30-100)$} \\
\hline & $\left(\mathrm{km}^{2}\right)$ & $\%$ & $\left(\mathrm{~km}^{2}\right)$ & $\%$ & $\left(\mathrm{~km}^{2}\right)$ & $\%$ & $\left(\mathrm{~km}^{2}\right)$ & $\%$ & $\left(\mathrm{~km}^{2}\right)$ & $\%$ \\
\hline Algeria & -268 & $0.0 \%$ & 268 & $0.7 \%$ & 0 & - & 0 & - & 0 & - \\
\hline Angola & $-190,987$ & $-98.3 \%$ & $-269,996$ & $-60.8 \%$ & 137,090 & $117.6 \%$ & 133,655 & $38.5 \%$ & 190,238 & $126.3 \%$ \\
\hline Benin & 0 & $0.0 \%$ & 0 & - & 0 & - & $-5,198$ & $-9.5 \%$ & 5,198 & $8.1 \%$ \\
\hline Botswana & $-156,215$ & $-32.2 \%$ & 151,820 & $160.1 \%$ & 3,827 & - & 567 & - & 0 & - \\
\hline Burkina Faso & 0 & - & -25 & $-0.1 \%$ & 5,389 & $12.7 \%$ & $-7,498$ & $-3.7 \%$ & 2,134 & $45.0 \%$ \\
\hline Burundi & 0 & - & -276 & $-32.1 \%$ & -540 & $-28.9 \%$ & -111 & $-0.5 \%$ & 927 & $336.4 \%$ \\
\hline Cameroon & 0 & $0.0 \%$ & $-2,418$ & $-56.4 \%$ & 1,511 & $19.0 \%$ & $-18,380$ & $-16.2 \%$ & 19,287 & $5.7 \%$ \\
\hline Cape Verde & 0 & $0.0 \%$ & 0 & - & 0 & - & 0 & - & 0 & - \\
\hline Central African Republic & 0 & - & 0 & - & 0 & - & $-23,133$ & $-20.5 \%$ & 23,133 & $4.6 \%$ \\
\hline Chad & -237 & $-0.7 \%$ & $-9,195$ & $-1.1 \%$ & 2,241 & $1.6 \%$ & 3,756 & $1.4 \%$ & 3,435 & - \\
\hline Comoros & 0 & $0.0 \%$ & 0 & - & 0 & - & 176 & $402.2 \%$ & -176 & $-19.9 \%$ \\
\hline Congo & 0 & $0.0 \%$ & 0 & - & 0 & - & 0 & - & 0 & $0.0 \%$ \\
\hline Congo, DRC & $-11,592$ & $-98.8 \%$ & $-47,801$ & $-63.7 \%$ & 13,711 & $33.2 \%$ & $-134,908$ & $-29.4 \%$ & 180,590 & $10.3 \%$ \\
\hline Cote d'Ivoire & 0 & $0.0 \%$ & 0 & - & 0 & - & $-3,511$ & $-52.7 \%$ & 3,511 & $1.1 \%$ \\
\hline Djibouti & $-13,032$ & $-92.5 \%$ & 13,032 & $203.0 \%$ & 0 & - & 0 & - & 0 & - \\
\hline Egypt & 0 & $0.0 \%$ & 0 & - & 0 & - & 0 & - & 0 & - \\
\hline Equatorial Guinea & 0 & $0.0 \%$ & 0 & - & 0 & - & 0 & - & 0 & $0.0 \%$ \\
\hline Eritrea & $-99,158$ & $-88.3 \%$ & 99,158 & $1307.1 \%$ & 0 & - & 0 & - & 0 & - \\
\hline Ethiopia & $-151,552$ & $-96.4 \%$ & $-122,837$ & $-14.7 \%$ & 152,510 & $195.6 \%$ & 121,818 & $189.4 \%$ & 61 & $7.4 \%$ \\
\hline Gabon & 0 & $0.0 \%$ & 0 & - & 0 & - & 0 & - & 0 & $0.0 \%$ \\
\hline Ghana & 0 & $0.0 \%$ & 0 & - & 0 & - & $-7,835$ & $-16.2 \%$ & 7,835 & $4.1 \%$ \\
\hline Guinea & 61 & $8.4 \%$ & 5,797 & $148.1 \%$ & 4,051 & $69.2 \%$ & $-17,185$ & $-12.9 \%$ & 7,276 & $7.1 \%$ \\
\hline Guinea-Bissau & 43 & $4.7 \%$ & 6,578 & - & 15,656 & - & $-22,277$ & $-73.1 \%$ & 0 & - \\
\hline Kenya & $-1,924$ & $-7.2 \%$ & $-179,902$ & $-49.9 \%$ & 64,693 & $82.0 \%$ & 98,760 & $115.2 \%$ & 18,373 & $55.6 \%$ \\
\hline Lesotho & $-2,282$ & $-7.4 \%$ & 2,282 & - & 0 & - & 0 & - & 0 & - \\
\hline Libya & 0 & $0.0 \%$ & 0 & $0.0 \%$ & 0 & - & 0 & - & 0 & - \\
\hline Madagascar & -261 & $-4.7 \%$ & $-37,823$ & $-57.2 \%$ & 18,757 & $15.8 \%$ & 5,219 & $2.0 \%$ & 14,108 & $10.4 \%$ \\
\hline Malawi & -357 & $-54.6 \%$ & $-47,014$ & $-68.1 \%$ & 27,654 & $98.1 \%$ & 19,343 & $98.8 \%$ & 373 & - \\
\hline Mali & $-3,425$ & $-1.4 \%$ & 31,341 & $4.8 \%$ & $-3,096$ & $-2.2 \%$ & $-25,456$ & $-12.0 \%$ & 636 & $60.8 \%$ \\
\hline Mauritania & 31,741 & $11.7 \%$ & $-10,301$ & $-1.4 \%$ & $-21,440$ & $-69.1 \%$ & 0 & - & 0 & - \\
\hline Morocco & 0 & $0.0 \%$ & 0 & - & 0 & - & 0 & - & 0 & - \\
\hline Mozambique & $-44,578$ & $-87.9 \%$ & $-136,287$ & $-53.4 \%$ & 65,073 & $66.7 \%$ & 70,031 & $25.9 \%$ & 45,761 & $37.9 \%$ \\
\hline Namibia & $-409,359$ & $-54.1 \%$ & 380,869 & $532.2 \%$ & 27,946 & - & 544 & - & 0 & - \\
\hline Niger & $-3,060$ & $-2.9 \%$ & $-9,587$ & $-0.9 \%$ & 12,169 & $27.3 \%$ & 477 & $3.3 \%$ & 0 & - \\
\hline Nigeria & 0 & $0.0 \%$ & $-28,855$ & $-46.3 \%$ & 5,777 & $3.6 \%$ & 1,169 & $0.4 \%$ & 21,909 & $5.8 \%$ \\
\hline Rwanda & 0 & - & -518 & $-28.6 \%$ & $-3,817$ & $-48.5 \%$ & 4,335 & $28.2 \%$ & 0 & - \\
\hline Sao Tome \& Principe & 0 & $0.0 \%$ & 0 & - & 0 & - & 0 & - & 0 & $0.0 \%$ \\
\hline Senegal & 0 & $0.0 \%$ & 8,049 & $20.0 \%$ & 19,902 & $36.5 \%$ & $-27,951$ & $-27.4 \%$ & 0 & - \\
\hline Seychelles & 0 & $0.0 \%$ & 0 & - & 0 & - & 0 & - & 0 & - \\
\hline Sierra Leone & 0 & $0.0 \%$ & 0 & $0.0 \%$ & 0 & $0.0 \%$ & $-1,924$ & $-6.7 \%$ & 1,924 & $5.0 \%$ \\
\hline Somalia & $-198,568$ & $-91.2 \%$ & 155,491 & $52.5 \%$ & 4,854 & $7.1 \%$ & 34,807 & $62.5 \%$ & 3,416 & - \\
\hline South Africa & $-176,144$ & $-14.8 \%$ & 139,066 & $512.6 \%$ & 20,468 & $739.0 \%$ & 14,615 & $662.5 \%$ & 1,995 & - \\
\hline Sudan & $-68,926$ & $-10.4 \%$ & 44,233 & $5.4 \%$ & $-24,274$ & $-11.7 \%$ & $-17,704$ & $-2.8 \%$ & 66,671 & $37.6 \%$ \\
\hline
\end{tabular}


Table 1 Absolute change in areas $\left(\mathrm{km}^{2}\right)$ for An. gambiae per country of Africa under scenario 1 (Continued)

\begin{tabular}{lccccccccccc}
\hline Swaziland & $-11,056$ & $-77.9 \%$ & 9,423 & $357.2 \%$ & 1,524 & - & 108 & - & 0 \\
Tanzania & $-1,477$ & $-30.1 \%$ & $-93,706$ & $-45.6 \%$ & $-43,689$ & $-24.8 \%$ & 34,179 & $8.3 \%$ & 104,692 & $71.4 \%$ \\
The Gambia & 0 & $0.0 \%$ & 0 & - & 70 & - & -70 & $-0.7 \%$ & 0 & - \\
Togo & 0 & $0.0 \%$ & 0 & - & 0 & - & $-1,293$ & $-12.3 \%$ & 1,293 & $2.8 \%$ \\
Tunisia & 0 & $0.0 \%$ & 0 & - & 0 & - & 0 & - & 0 & - \\
Uganda & 0 & $0.0 \%$ & -383 & $-20.1 \%$ & -519 & $-24.8 \%$ & $-24,531$ & $-41.2 \%$ & 25,433 & $14.0 \%$ \\
Western Sahara & 410 & $0.2 \%$ & -410 & $-0.6 \%$ & 0 & - & 0 & - & 0 & - \\
Zambia & $-75,481$ & $-96.6 \%$ & $-280,531$ & $-45.0 \%$ & 182,310 & $385.4 \%$ & 173,703 & $3221.2 \%$ & 0 & - \\
Zimbabwe & $-90,517$ & $-37.7 \%$ & 79,923 & $57.9 \%$ & 8,760 & $65.2 \%$ & 1,834 & - & 0 & - \\
Grand total & $-\mathbf{1 , 6 7 8 , 2 0 0}$ & $-\mathbf{1 5 . 9} \%$ & $-\mathbf{1 5 0 , 5 3 4}$ & $-\mathbf{1 . 9} \%$ & $\mathbf{6 9 8 , 4 7 7}$ & $\mathbf{4 0 . 6 \%}$ & $\mathbf{3 7 8 , 9 4 6}$ & $\mathbf{8 . 6 \%}$ & $\mathbf{7 5 1 , 3 1 1}$ & $\mathbf{1 3 . 9} \%$ \\
\hline
\end{tabular}

Values obtained by subtracting the Eco-climatic index (EI) estimates for future An. gambiae distribution from projected scenario 1 criteria to the El estimates obtained under current climate for each country. Percentages (\%) were calculated by dividing each absolute area change to the current area value per country.

approximation of $851,087 \mathrm{~km}^{2}$ reduction in area is estimated for Class 5 under scenario 2. Overall, the results show that if the climate changes according to scenario 1 , An. gambiae will most likely expand its range from zones of no and low suitability into zones of sequential; high risk of permanent establishment and long-term survival. The African countries to be affected under this scenario include Angola, Burundi, Comoros, Ethiopia, Kenya, Malawi, Mali, South Africa, Tanzania and Zambia (Table 1). Under climate change scenario 2, An. gambiae will possibly concentrate its distribution in areas with sequential and high risk of permanent establishment. Angola, Cameroon, Ethiopia, Guinea, Mozambique, Niger, Sierra Leone, South Africa, Uganda, Zambia and Zimbabwe are the countries predicted to be prone to a $50 \%$ total country area shift from no and low survival into areas of sequential and high risk of permanent establishment of An. gambiae (Table 2).

Results for $A n$. arabiensis under projected scenarios 1 and 2 are presented in Tables 3 and 4, respectively. Under the first climate change scenario (Table 3), area losses of $847,964 \mathrm{~km}^{2}$ (Class 1) and 780,622 (Class 2) were estimated. Further, area increments of $540,783 \mathrm{~km}^{2}$ and 1,087,803 $\mathrm{km}^{2}$ were projected for Classes 3 and 4, respectively with no evident change of area for class 5. Anopheles arabiensis displays a considerable loss of area equal to $1,515,491 \mathrm{~km}^{2}$ (Class 1 ) and a gain of $1,670,823 \mathrm{~km}^{2}$ (C 2) with scenario 2 . Within this scenario, an additional loss of $405,522 \mathrm{~km}^{2}$ may occur in Class 3 and increase in two areas evaluated at $249,141 \mathrm{~km}^{2}$ (Class 4) and at $1,050 \mathrm{~km}^{2}$ (Class 5). From these results, An. arabiensis will most likely be found in Angola, Botswana, Burundi, Congo DRC, Djibouti, Ethiopia, Kenya, Malawi, Namibia, Rwanda, South Africa, Sudan, Swaziland, The Gambia, Uganda, and Zimbabwe (Table 3). Area increases were predicted in these countries belonging to Classes 3 and 4 under climate change scenario 1 . In contrast with climate change scenario 2 , majority of area shifts will converge in zones with very little suitability for survival of An. Arabiensis (Table 4).
Figures 2 and 3 represent the summary of absolute change in area per country for An. gambiae and An. arabiensis, respectively. A bar graph was used to illustrate visually and display the amounts of absolute change of area. The display allows us to compare levels of suitability for the Anopheles species, and to quickly make generalizations about possible change of ranges with changing climate. The height of a bar indicates the proportion of area that is increasing or decreasing. A bar displayed on the positive plane of the axes represents an increasing area where as a reverse bar represents a decreasing area. Such quantitative chart maps are useful for decision-making, they easily guide on the identification of countries with high risk of permanent establishment of malaria vectors due to potential change in climate. Overall, the proportion of areas that is increasing or decreasing in level of survival for malaria vectors is more pronounced in eastern and southern African countries than in western African countries. Angola, Ethiopia, Kenya, Mozambique, Tanzania, South Africa and Zambia appear most likely to be affected in terms of absolute change of malaria vectors suitability zones under the selected climate change scenarios.

\section{Discussion}

The importance of projecting the future spread of malaria under various climate change scenarios cannot be overemphasized as it helps policy-makers to identify vulnerable communities and to better manage malaria epidemics. In such projections, various climate models have been applied producing different climate changes and correspondingly shift the future distribution and variability of malaria transmission. However, planning and adapting to the projected boundary shifts of malaria vectors under changing climate, necessitates innovative approaches.

We provide an improved measure of malaria risk projections by defining geographical locations favourable for the malaria vectors establishment and survival. We define areas likely to become more suitable for transmission of malaria 
Table 2 Absolute change in areas $\left(\mathrm{km}^{2}\right)$ for An. gambiae per country of Africa under scenario 2

\begin{tabular}{|c|c|c|c|c|c|c|c|c|c|c|}
\hline \multirow[t]{2}{*}{ Countries } & \multicolumn{2}{|c|}{$E I=0$} & \multicolumn{2}{|c|}{$E I=(0.1-5)$} & \multicolumn{2}{|c|}{$E I=(5-10)$} & \multicolumn{2}{|c|}{$E I=(10-30)$} & \multicolumn{2}{|c|}{$E I=(30-100)$} \\
\hline & $\left(\mathrm{km}^{2}\right)$ & $\%$ & $\left(\mathrm{~km}^{2}\right)$ & $\%$ & $\left(\mathrm{~km}^{2}\right)$ & $\%$ & $\left(\mathrm{~km}^{2}\right)$ & $\%$ & $\left(\mathrm{~km}^{2}\right)$ & $\%$ \\
\hline Algeria & $-13,395$ & $-0.6 \%$ & 13,395 & $35.7 \%$ & 0 & - & 0 & - & 0 & - \\
\hline Angola & $-18,304$ & $-9.4 \%$ & $-262,407$ & $-59.0 \%$ & 144,986 & $124.4 \%$ & 81,332 & $23.4 \%$ & 54,392 & $36.1 \%$ \\
\hline Benin & 0 & $0.0 \%$ & 0 & - & 0 & - & 9,805 & $18.0 \%$ & $-9,805$ & $-15.4 \%$ \\
\hline Botswana & $-76,585$ & $-15.8 \%$ & 64,040 & $67.5 \%$ & 11,447 & - & 1,098 & - & 0 & - \\
\hline Burkina Faso & 0 & - & $-7,385$ & $-28.2 \%$ & 6,067 & $14.3 \%$ & 5,584 & $2.8 \%$ & $-4,266$ & $-90.0 \%$ \\
\hline Burundi & 0 & - & 31 & $3.6 \%$ & 380 & $20.3 \%$ & -135 & $-0.6 \%$ & -276 & $-100.0 \%$ \\
\hline Cameroon & 31 & $5.5 \%$ & $-2,620$ & $-61.2 \%$ & 4,795 & $60.2 \%$ & 126,511 & $111.2 \%$ & $-128,716$ & $-37.9 \%$ \\
\hline Cape Verde & 0 & $0.0 \%$ & 0 & - & 0 & - & 0 & - & 0 & - \\
\hline Central African Republic & 0 & - & 0 & - & 0 & - & 124,589 & $110.5 \%$ & $-124,589$ & $-24.6 \%$ \\
\hline Chad & $-1,036$ & $-3.0 \%$ & $-52,916$ & $-6.4 \%$ & 43,927 & $30.9 \%$ & 10,026 & $3.7 \%$ & 0 & - \\
\hline Comoros & 0 & $0.0 \%$ & 0 & - & 0 & - & 840 & $1915.1 \%$ & -840 & $-94.7 \%$ \\
\hline Congo & 0 & $0.0 \%$ & 0 & - & 0 & - & 0 & - & 0 & $0.0 \%$ \\
\hline Congo, DRC & $-1,022$ & $-8.7 \%$ & 2,929 & $3.9 \%$ & 7,064 & $17.1 \%$ & 131,275 & $28.6 \%$ & $-140,247$ & $-8.0 \%$ \\
\hline Cote d'Ivoire & 0 & $0.0 \%$ & 0 & - & 2,002 & - & 32,490 & $487.5 \%$ & $-34,492$ & $-11.0 \%$ \\
\hline Djibouti & $-13,118$ & $-93.1 \%$ & 13,118 & $204.3 \%$ & 0 & - & 0 & - & 0 & - \\
\hline Egypt & 0 & $0.0 \%$ & 0 & - & 0 & - & 0 & - & 0 & - \\
\hline Equatorial Guinea & 0 & $0.0 \%$ & 0 & - & 0 & - & 0 & - & 0 & $0.0 \%$ \\
\hline Eritrea & $-6,757$ & $-6.0 \%$ & 6,757 & $89.1 \%$ & 0 & - & 0 & - & 0 & - \\
\hline Ethiopia & $-56,353$ & $-35.8 \%$ & $-18,488$ & $-2.2 \%$ & 69,136 & $88.7 \%$ & 6,531 & $10.2 \%$ & -826 & $-100.0 \%$ \\
\hline Gabon & 0 & $0.0 \%$ & 0 & - & 0 & - & 0 & - & 0 & $0.0 \%$ \\
\hline Ghana & 0 & $0.0 \%$ & 0 & - & 0 & - & 12,508 & $25.9 \%$ & $-12,508$ & $-6.5 \%$ \\
\hline Guinea & 90 & $12.5 \%$ & 16,541 & $422.6 \%$ & 17,106 & $292.4 \%$ & 32,242 & $24.2 \%$ & $-65,979$ & $-64.8 \%$ \\
\hline Guinea-Bissau & 124 & $13.3 \%$ & 17,947 & - & 12,398 & - & $-30,469$ & $-100.0 \%$ & 0 & - \\
\hline Kenya & -896 & $-3.4 \%$ & 3,260 & $0.9 \%$ & $-4,980$ & $-6.3 \%$ & 7,993 & $9.3 \%$ & $-5,376$ & $-16.3 \%$ \\
\hline Lesotho & 0 & $0.0 \%$ & 0 & - & 0 & - & 0 & - & 0 & - \\
\hline Libya & 0 & $0.0 \%$ & 0 & $0.0 \%$ & 0 & - & 0 & - & 0 & - \\
\hline Madagascar & -394 & $-7.0 \%$ & $-46,954$ & $-71.0 \%$ & $-50,862$ & $-42.8 \%$ & 138,412 & $52.1 \%$ & $-40,203$ & $-29.7 \%$ \\
\hline Malawi & 30 & $4.5 \%$ & 6,601 & $9.6 \%$ & $-3,273$ & $-11.6 \%$ & $-3,357$ & $-17.2 \%$ & 0 & - \\
\hline Mali & $-35,762$ & $-14.2 \%$ & 17,630 & $2.7 \%$ & 41,122 & $28.9 \%$ & $-21,945$ & $-10.3 \%$ & $-1,046$ & $-100.0 \%$ \\
\hline Mauritania & 1,426 & $0.5 \%$ & 10,121 & $1.4 \%$ & $-11,546$ & $-37.2 \%$ & 0 & - & 0 & - \\
\hline Morocco & 0 & $0.0 \%$ & 0 & - & 0 & - & 0 & - & 0 & - \\
\hline Mozambique & -496 & $-1.0 \%$ & $-161,657$ & $-63.4 \%$ & 70,282 & $72.1 \%$ & 156,528 & $58.0 \%$ & $-64,656$ & $-53.5 \%$ \\
\hline Namibia & $-8,608$ & $-1.1 \%$ & $-54,034$ & $-75.5 \%$ & 60,700 & - & 1,942 & - & 0 & - \\
\hline Niger & $-41,835$ & $-40.1 \%$ & $-37,796$ & $-3.7 \%$ & 77,389 & $173.6 \%$ & 2,242 & $15.5 \%$ & 0 & - \\
\hline Nigeria & 0 & $0.0 \%$ & $-43,815$ & $-70.3 \%$ & 10,834 & $6.8 \%$ & 90,909 & $29.3 \%$ & $-57,928$ & $-15.2 \%$ \\
\hline Rwanda & 0 & - & 335 & $18.5 \%$ & 908 & $11.5 \%$ & $-1,244$ & $-8.1 \%$ & 0 & - \\
\hline Sao Tome \& Principe & 0 & $0.0 \%$ & 0 & - & 0 & - & 0 & - & 0 & $0.0 \%$ \\
\hline Senegal & 0 & $0.0 \%$ & 20,008 & $49.8 \%$ & 42,788 & $78.5 \%$ & $-62,796$ & $-61.5 \%$ & 0 & - \\
\hline Seychelles & 0 & $0.0 \%$ & 0 & - & 0 & - & 0 & - & 0 & - \\
\hline Sierra Leone & 0 & $0.0 \%$ & 1,852 & $91.8 \%$ & 2,736 & $96.9 \%$ & 21,979 & $76.0 \%$ & $-26,568$ & $-68.6 \%$ \\
\hline Somalia & $-144,129$ & $-66.2 \%$ & 113,211 & $38.2 \%$ & 8,157 & $12.0 \%$ & 19,397 & $34.8 \%$ & 3,364 & - \\
\hline South Africa & -211 & $0.0 \%$ & $-13,589$ & $-50.1 \%$ & 5,350 & $193.1 \%$ & 6,716 & $304.4 \%$ & 1,735 & - \\
\hline Sudan & $-6,670$ & $-1.0 \%$ & $-30,065$ & $-3.6 \%$ & $-17,980$ & $-8.7 \%$ & 77,773 & $12.4 \%$ & $-23,059$ & $-13.0 \%$ \\
\hline
\end{tabular}


Table 2 Absolute change in areas $\left(\mathrm{km}^{2}\right)$ for An. gambiae per country of Africa under scenario 2 (Continued)

\begin{tabular}{lcccccccccc}
\hline Swaziland & -404 & $-2.8 \%$ & 55 & $2.1 \%$ & 350 & - & 0 & - & 0 & - \\
Tanzania & -184 & $-3.7 \%$ & $-25,898$ & $-12.6 \%$ & $-8,435$ & $-4.8 \%$ & 34,099 & $8.3 \%$ & 416 & $0.3 \%$ \\
The Gambia & 0 & $0.0 \%$ & 0 & - & 5,568 & - & $-5,568$ & $-56.9 \%$ & 0 & - \\
Togo & 0 & $0.0 \%$ & 0 & - & 0 & - & 10,584 & $101.0 \%$ & $-10,584$ & $-23.2 \%$ \\
Tunisia & 0 & $0.0 \%$ & 0 & - & 0 & - & 0 & - & 0 & - \\
Uganda & 0 & $0.0 \%$ & 183 & $9.6 \%$ & 1,491 & $71.3 \%$ & 102,432 & $172.2 \%$ & $-104,106$ & $-57.2 \%$ \\
Western Sahara & 12 & $0.0 \%$ & -12 & $0.0 \%$ & 0 & - & 0 & - & 0 & - \\
Zambia & $-26,800$ & $-34.3 \%$ & $-154,013$ & $-24.7 \%$ & 118,504 & $250.5 \%$ & 62,310 & $1155.5 \%$ & 0 & - \\
Zimbabwe & $-11,813$ & $-4.9 \%$ & $-7,144$ & $-5.2 \%$ & 13,908 & $103.5 \%$ & 5,050 & - & 0 & - \\
Grand total & $-\mathbf{4 6 3 , 0 5 9}$ & $-\mathbf{4 . 4 \%}$ & $-\mathbf{6 0 9 , 7 4 4}$ & $\mathbf{- 7 . 7 \%}$ & $\mathbf{6 8 5 , 0 6 0}$ & $\mathbf{3 9 . 8} \%$ & $\mathbf{1 , 2 3 8 , 8 2 9}$ & $\mathbf{2 8 . 3} \%$ & $-\mathbf{8 5 1 , 0 8 7}$ & $\mathbf{- 1 5 . 8 \%}$ \\
\hline
\end{tabular}

Values were obtained by subtracting the Eco-climatic index (EI) estimates for future An. gambiae distribution from projected scenario 2 criteria to the El estimates obtained under current climate for each country. Percentages (\%) were calculated by dividing each absolute area change to the current area value per country.

owing to suitable areas for the vectors promoting parasite survival and transmission by vector. Survival of the vectors from year-to-year is a prerequisite for malaria endemicity and remains a key component in the epidemiology and spread of the disease. Our predictions take into account the differential impact of climate change on the dynamics of these key malaria vectors as dictated by their individual dynamics and life cycle parameters which obviously impart differently on the patterns and spread of malaria.

Within the African setting, the suitability for malaria transmission has been projected to change by varying degrees and directions over much of the Sahel, eastern and southern Africa $[9,11]$. The population at risk has been projected to decrease across West Africa and the Sahel because of a drier climate, $[6,18]$ but to increase in both East and South Africa [6,26]. In the same light, an earlier study [14] predicted likely shifts in the boundaries of An. gambiae and An. arabiensis southwards and eastwards of Africa, respectively, rather than jumps into quite different climatic environments. Animated by the need for local level-based malaria risk projections, this study represents advancement in our ability to predict future malaria trends especially at the country level. Our results illustrate the amounts of absolute change of area per country that allows us to compare levels of suitability for the Anopheles species, and to quickly make generalizations about possible change of ranges with changing climate.

Predicted areas in terms of absolute change for suitability or establishment of both vectors vary under the two climate scenarios (1 and 2) considered. This finding indicates that the susceptibility in their distribution is dictated by variable climatic patterns notably temperature, rainfall and humidity. These species are known to live in sympatry although adaptive preference in ecology for these species has been highlighted with An. gambiae preferring wet and humid zones, and An. arabiensis drier climates [27]. An added biological complexity is that there are distinct chromosomal forms of An. gambiae with distinct climatic preferences [28] although there is not enough available data to separately map these forms. Given that the greatest effect of climate change on transmission is likely to be observed at the extremes of temperature ranges [3], it was surprising that under scenario 1, adaptation to areas of long term survival (class 5) was evident for An. gambiae but not for An. arabiensis. Therefore, the combined effect of temporal and spatial changes in temperature, precipitation and humidity are expected to occur under different climate change scenarios which will affect the biology and ecology of vectors and intermediate hosts and consequently the risk of disease transmission [3]. The changed area of establishment is likely to be affected by intensity of vector control efforts and health infrastructure. For example, following long term use of IRS and ITNs, there has been a proportionate increase in An. arabiensis compared to its closely related sibling species An. gambiae s.s in East Africa [29,30], as this species is less susceptible to the indoor control strategies because of its plastic and more exophilic tendencies.

We have presented a country-based projection of malaria transmission under different climate change scenarios with key parameters -temperature, rainfall and humidity. Although we do not assert that climate alone is the main determinant factor for Anopheles species existence, it is the only factor with available country data that provides an initial estimate of the potential range of Anopheles species. The present study should rather be seen as an illustration of the substantial influence, which the direct effects of climate change may represent to malaria vectors redistribution within each African country. The results presented here should be interpreted as an indication of the sensitivity of malaria vectors to climatic changes, particularly temperature rise. More elaborate future risk assessments of climate change on malaria vectors in Africa will ultimately need to include the ecology and behavior of the host and vector, non-climatic factors such as gross domestic product (GDP), future population growth 
Table 3 Absolute change in areas $\left(\mathrm{km}^{2}\right)$ for An. arabiensis per African country under scenario 1

\begin{tabular}{|c|c|c|c|c|c|c|c|c|c|c|}
\hline \multirow[t]{2}{*}{ Countries } & \multicolumn{2}{|c|}{$E I=0$} & \multicolumn{2}{|c|}{$E I=(0.1-5)$} & \multicolumn{2}{|c|}{$E I=(5-10)$} & \multicolumn{2}{|c|}{$E I=(10-30)$} & \multicolumn{2}{|c|}{$E I=(30-100)$} \\
\hline & $\left(\mathrm{km}^{2}\right)$ & $\%$ & $\left(\mathrm{~km}^{2}\right)$ & $\%$ & $\left(\mathrm{~km}^{2}\right)$ & $\%$ & $\left(\mathrm{~km}^{2}\right)$ & $\%$ & $\left(\mathrm{~km}^{2}\right)$ & $\%$ \\
\hline Algeria & $-18,029$ & $-0.9 \%$ & 18,029 & $7.0 \%$ & 0 & - & 0 & - & 0 & - \\
\hline Angola & -119 & $-5.3 \%$ & $-122,371$ & $-13.6 \%$ & 42,468 & $16.3 \%$ & 80,021 & $90.1 \%$ & 0 & - \\
\hline Benin & 0 & $0.0 \%$ & 9 & - & -9 & $0.0 \%$ & 0 & - & 0 & - \\
\hline Botswana & $-4,875$ & $-18.7 \%$ & $-201,103$ & $-64.4 \%$ & $-102,862$ & $-45.3 \%$ & 308,841 & $2144.3 \%$ & 0 & - \\
\hline Burkina Faso & 0 & - & 0 & - & 2,463 & $0.9 \%$ & $-2,463$ & $-24.0 \%$ & 0 & - \\
\hline Burundi & 0 & $0.0 \%$ & -829 & $-3.2 \%$ & 829 & $54.9 \%$ & 0 & - & 0 & - \\
\hline Cameroon & $-90,100$ & $-78.7 \%$ & 91,441 & $33.5 \%$ & $-1,342$ & $-1.7 \%$ & 0 & - & 0 & - \\
\hline Cape Verde & 0 & $0.0 \%$ & 0 & - & 0 & - & 0 & - & 0 & - \\
\hline Central African Republic & 0 & - & 62,703 & $15.6 \%$ & $-62,703$ & $-28.7 \%$ & 0 & - & 0 & - \\
\hline Chad & -148 & $-4.1 \%$ & $-38,316$ & $-7.4 \%$ & 38,464 & $5.2 \%$ & 0 & - & 0 & - \\
\hline Comoros & 0 & $0.0 \%$ & 0 & - & 0 & $0.0 \%$ & 0 & - & 0 & - \\
\hline Congo & $-107,537$ & $-83.9 \%$ & 107,537 & $49.5 \%$ & 0 & - & 0 & - & 0 & - \\
\hline Congo, DRC & $-144,492$ & $-49.6 \%$ & 139,848 & $6.9 \%$ & 4,643 & $53.3 \%$ & 0 & - & 0 & - \\
\hline Cote d'Ivoire & -150 & $-5.5 \%$ & -892 & $-0.5 \%$ & 1,732 & $1.2 \%$ & -690 & $-100.0 \%$ & 0 & - \\
\hline Djibouti & 0 & $0.0 \%$ & $-4,091$ & $-27.0 \%$ & 4,091 & $79.8 \%$ & 0 & - & 0 & - \\
\hline Egypt & 0 & $0.0 \%$ & 0 & $0.0 \%$ & 0 & - & 0 & - & 0 & - \\
\hline Equatorial Guinea & $-1,598$ & $-6.0 \%$ & 1,598 & $1943.1 \%$ & 0 & - & 0 & - & 0 & - \\
\hline Eritrea & -824 & $-28.4 \%$ & $-17,267$ & $-22.3 \%$ & 10,546 & $26.6 \%$ & 7,545 & - & 0 & - \\
\hline Ethiopia & -856 & $-34.4 \%$ & $-267,550$ & $-31.1 \%$ & 257,782 & $97.1 \%$ & 10,624 & $153.7 \%$ & 0 & - \\
\hline Gabon & $-60,795$ & $-33.3 \%$ & 60,795 & $75.4 \%$ & 0 & - & 0 & - & 0 & - \\
\hline Ghana & 0 & $0.0 \%$ & $-5,698$ & $-59.8 \%$ & 14,531 & $7.8 \%$ & $-8,833$ & $-19.8 \%$ & 0 & - \\
\hline Guinea & 2,714 & $109.6 \%$ & $-2,196$ & $-0.9 \%$ & -518 & $-9.7 \%$ & 0 & - & 0 & - \\
\hline Guinea-Bissau & 0 & $0.0 \%$ & 0 & $0.0 \%$ & 0 & - & 0 & - & 0 & - \\
\hline Kenya & $-1,298$ & $-46.0 \%$ & $-162,139$ & $-52.5 \%$ & 57,455 & $27.5 \%$ & 105,982 & $166.2 \%$ & 0 & - \\
\hline Lesotho & $-29,693$ & $-96.4 \%$ & 29,693 & - & 0 & - & 0 & - & 0 & - \\
\hline Libya & 0 & $0.0 \%$ & 0 & $0.0 \%$ & 0 & - & 0 & - & 0 & - \\
\hline Madagascar & $-2,126$ & $-21.9 \%$ & $-19,475$ & $-5.7 \%$ & 3,924 & $2.3 \%$ & 17,677 & $23.5 \%$ & 0 & - \\
\hline Malawi & 0 & - & $-2,431$ & $-2.2 \%$ & 2,431 & $54.7 \%$ & 0 & - & 0 & - \\
\hline Mali & -540 & $-1.5 \%$ & $-32,144$ & $-4.8 \%$ & 39,024 & $7.2 \%$ & $-6,340$ & $-100.0 \%$ & 0 & - \\
\hline Mauritania & $-2,013$ & $-1.3 \%$ & -864 & $-0.1 \%$ & 2,877 & $1.2 \%$ & 0 & - & 0 & - \\
\hline Morocco & 0 & $0.0 \%$ & 0 & - & 0 & - & 0 & - & 0 & - \\
\hline Mozambique & -92 & $-2.6 \%$ & $-124,300$ & $-39.3 \%$ & 97,249 & $30.5 \%$ & 27,143 & $17.5 \%$ & 0 & - \\
\hline Namibia & $-47,193$ & $-24.1 \%$ & $-3,795$ & $-1.4 \%$ & $-49,822$ & $-21.4 \%$ & 100,810 & $77.0 \%$ & 0 & - \\
\hline Niger & -441 & $-4.4 \%$ & $-43,709$ & $-6.0 \%$ & 40,767 & $9.7 \%$ & 3,383 & $14.8 \%$ & 0 & - \\
\hline Nigeria & 1,868 & $30.4 \%$ & 26,586 & $8.4 \%$ & $-28,454$ & $-4.8 \%$ & 0 & - & 0 & - \\
\hline Rwanda & -2 & $-100.0 \%$ & $-4,175$ & $-16.8 \%$ & 4,177 & $3822.3 \%$ & 0 & - & 0 & - \\
\hline Sao Tome \& Principe & 0 & $0.0 \%$ & 0 & - & 0 & - & 0 & - & 0 & - \\
\hline Senegal & 0 & $0.0 \%$ & $-11,289$ & $-19.4 \%$ & 11,289 & $8.1 \%$ & 0 & - & 0 & - \\
\hline Seychelles & 0 & $0.0 \%$ & 0 & - & 0 & - & 0 & - & 0 & - \\
\hline Sierra Leone & 1,312 & $33.9 \%$ & $-1,312$ & $-1.9 \%$ & 0 & - & 0 & - & 0 & - \\
\hline Somalia & $-4,165$ & $-41.7 \%$ & $-46,632$ & $-9.4 \%$ & 39,747 & $45.7 \%$ & 11,050 & $24.8 \%$ & 0 & - \\
\hline South Africa & $-320,421$ & $-35.1 \%$ & 190,047 & $72.8 \%$ & 63,538 & $185.0 \%$ & 66,837 & $568.5 \%$ & 0 & - \\
\hline Sudan & $-3,634$ & $-2.9 \%$ & $-73,782$ & $-9.0 \%$ & $-149,745$ & $-12.1 \%$ & 227,160 & $71.6 \%$ & 0 & - \\
\hline
\end{tabular}


Table 3 Absolute change in areas $\left(\mathbf{k m}^{2}\right)$ for An. arabiensis per African country under scenario 1 (Continued)

\begin{tabular}{lcccccccccc}
\hline Swaziland & -27 & $-33.3 \%$ & $-2,626$ & $-32.2 \%$ & $-3,108$ & $-37.9 \%$ & 5,761 & $1484.4 \%$ & 0 & - \\
Tanzania & $-1,285$ & $-35.4 \%$ & $-180,302$ & $-29.5 \%$ & 139,132 & $70.0 \%$ & 42,455 & $32.7 \%$ & 0 & - \\
The Gambia & 0 & $0.0 \%$ & $-5,206$ & $-79.4 \%$ & 5,206 & $161.0 \%$ & 0 & - & 0 & - \\
Togo & 0 & $0.0 \%$ & 10,110 & - & $-8,555$ & $-16.1 \%$ & $-1,555$ & $-51.3 \%$ & 0 & - \\
Tunisia & 0 & $0.0 \%$ & 0 & - & 0 & - & 0 & - & 0 & - \\
Uganda & -187 & $-100.0 \%$ & $-21,898$ & $-13.9 \%$ & 2,798 & $3.5 \%$ & 19,287 & $211.0 \%$ & 0 & - \\
Western Sahara & $-5,159$ & $-4.4 \%$ & 5,159 & $3.4 \%$ & 0 & - & 0 & - & 0 & - \\
Zambia & -900 & $-100.0 \%$ & $-44,041$ & $-7.0 \%$ & 44,941 & $36.8 \%$ & 0 & - & 0 & - \\
Zimbabwe & $-5,556$ & $-96.0 \%$ & $-83,346$ & $-37.8 \%$ & 15,793 & $11.3 \%$ & $\mathbf{7 3 , 1 0 9}$ & $\mathbf{2 8 9 . 4 \%}$ & 0 & - \\
Grand total & $-\mathbf{8 4 7 , 9 6 4}$ & $-\mathbf{1 1 . 3} \%$ & $-\mathbf{7 8 0 , 6 2 2}$ & $-\mathbf{5 . 6 \%}$ & $\mathbf{5 4 0 , 7 8 3}$ & $\mathbf{7 . 3} \%$ & $\mathbf{1 , 0 8 7 , 8 0 3}$ & $\mathbf{9 3 . 7 \%}$ & $\mathbf{0}$ & - \\
\hline
\end{tabular}

Values obtained by subtracting the Eco-climatic index (EI) estimates for future An. arabiensis distribution from projected scenario 1 criteria to the El estimates obtained under current climate for each country. Percentages (\%) were calculated by dividing each absolute area change to the current area value per country.

and migration, socioeconomic status, urbanization and malaria control status and vector in each country.

\section{Recommendations}

The overall outcome of the study has led to recommendations in form of best practices which if put in place could help in preventing malaria under a changing climate context. The proposed guidelines highlight potential actions and suggestions for mitigating the negative impact of climate change on malaria risk in Africa, which can be extended to other vector borne diseases.

\section{Technical innovation}

A combined application of computing technology, telephone networks, geographical information system (GIS) and other technologies can be invaluable in the development of computerized tools for use at local, regional and continental levels for effective management of malaria. These tools include relevant literature, decision support software, and access to one or more central databases of Anopheles biology, ecology, population densities and related climate information in a GIS database for adequate monitoring of the species shifts [31-36]. Such innovative tools can be used to alert officials on impending outbreaks days or months ahead. Innovative investigations could also be oriented towards developing suitable field tools for monitoring essential characteristics of vector populations for improved understanding of their adaptive capacity with changing climate.

Strengthening internal and cross-border vector surveillance A step-by-step approach to a regional framework for implementing integrated malaria vector management from the district to regional and Africa wide level is needed [31]. It is essential that countries and regional blocks in Africa establish appropriate plans for deploying an optimum mix of interventions measures. Such a framework will be helpful in guiding member countries in selectively applying the various available vector control tools based on the epidemiological situation, vector bionomics and behavior, and the socio-behavioral characteristics of the community. This might enhance malaria surveillance within a country and in regions and help in case of urgent need for action, to contain the spread of the vectors. Through regular exchange forums and technical consultations it should be possible to identify, share and disseminate best practices in malaria control including the development of projects with crossborder activities to enhance integration and help in developing a strong Africa union.

\section{Research}

Research is important in understanding and implementing adaptive measures to climate change in Africa. The knowledge gained through research will contribute in laying a foundation for future planning. An investment by African governments and industries in science and technology development is deemed necessary in order to fulfill their pledges [32]. Potential research areas of focus will include an understanding of: 1) the dynamics of malaria transmission by vector populations and the risk of exposure for human populations in various ecosystems; 2) the factors affecting Anopheles larval survival and mechanisms controlling adult production in aquatic habitats, and 3) the selective forces that cause some mosquitoes like $A n$. gambiae to specialize on humans.

\section{Enhancing information management and knowledge sharing} Information, education and communication are vital means for improving adaptation to Anopheles control; in which case, increased awareness for generations to begin coping with climate change is essential. Teaching the science of climate change in schools may be instituted with a focus on practical skills for the management of climate risks. Dissemination can be facilitated through the media and information tools such as television programmes, short thematic films, brochures, booklets. Special education and 
Table 4 Absolute change in areas $\left(\mathrm{km}^{2}\right)$ for An. arabiensis per African country under scenario 2

\begin{tabular}{|c|c|c|c|c|c|c|c|c|c|c|}
\hline \multirow[t]{2}{*}{ Countries } & \multicolumn{2}{|c|}{$E I=0$} & \multicolumn{2}{|c|}{$E I=(0.1-5)$} & \multicolumn{2}{|c|}{$E I=(5-10)$} & \multicolumn{2}{|c|}{$E I=(10-30)$} & \multicolumn{2}{|c|}{$E I=(30-100)$} \\
\hline & $\left(\mathrm{km}^{2}\right)$ & $\%$ & $\left(\mathrm{~km}^{2}\right)$ & $\%$ & $\left(\mathrm{~km}^{2}\right)$ & $\%$ & $\left(\mathrm{~km}^{2}\right)$ & $\%$ & $\left(\mathrm{~km}^{2}\right)$ & $\%$ \\
\hline Algeria & $-65,468$ & $-3.2 \%$ & 65,468 & $25.5 \%$ & 0 & - & 0 & - & 0 & - \\
\hline Angola & 6,405 & $285.3 \%$ & 14,451 & $1.6 \%$ & 12,113 & $4.6 \%$ & $-32,969$ & $-37.1 \%$ & 0 & - \\
\hline Benin & 0 & $0.0 \%$ & 84,032 & - & $-84,032$ & $-71.0 \%$ & 0 & - & 0 & - \\
\hline Botswana & $-23,109$ & $-88.5 \%$ & $-218,861$ & $-70.1 \%$ & $-106,614$ & $-47.0 \%$ & 348,584 & $2420.2 \%$ & 0 & - \\
\hline Burkina Faso & 0 & - & 1,794 & - & 8,479 & $3.2 \%$ & $-10,273$ & $-100.0 \%$ & 0 & - \\
\hline Burundi & 0 & $0.0 \%$ & 1,510 & $5.9 \%$ & $-1,510$ & $-100.0 \%$ & 0 & - & 0 & - \\
\hline Cameroon & $-92,954$ & $-81.2 \%$ & 104,920 & $38.5 \%$ & $-12,256$ & $-15.5 \%$ & 290 & - & 0 & - \\
\hline Cape Verde & 0 & $0.0 \%$ & 0 & - & 0 & - & 0 & - & 0 & - \\
\hline Central African Republic & 1,072 & - & 145,689 & $36.3 \%$ & $-146,761$ & $-67.3 \%$ & 0 & - & 0 & - \\
\hline Chad & 0 & $0.0 \%$ & $-21,437$ & $-4.1 \%$ & $-9,166$ & $-1.2 \%$ & 30,603 & - & 0 & - \\
\hline Comoros & 0 & $0.0 \%$ & 687 & - & -687 & $-73.9 \%$ & 0 & - & 0 & - \\
\hline Congo & $-122,043$ & $-95.2 \%$ & 122,043 & $56.2 \%$ & 0 & - & 0 & - & 0 & - \\
\hline Congo, DRC & $-174,290$ & $-59.8 \%$ & 182,956 & $9.0 \%$ & $-8,666$ & $-99.5 \%$ & 0 & - & 0 & - \\
\hline Cote d'Ivoire & 143 & $5.3 \%$ & 123,466 & $72.9 \%$ & $-122,918$ & $-82.9 \%$ & -690 & $-100.0 \%$ & 0 & - \\
\hline Djibouti & 0 & $0.0 \%$ & 5,124 & $33.8 \%$ & $-5,124$ & $-100.0 \%$ & 0 & - & 0 & - \\
\hline Egypt & 0 & $0.0 \%$ & 0 & $0.0 \%$ & 0 & - & 0 & - & 0 & - \\
\hline Equatorial Guinea & $-26,279$ & $-98.8 \%$ & 26,221 & $31886.6 \%$ & 58 & - & 0 & - & 0 & - \\
\hline Eritrea & -589 & $-20.3 \%$ & $-12,907$ & $-16.7 \%$ & 9,293 & $23.4 \%$ & 4,203 & - & 0 & - \\
\hline Ethiopia & -896 & $-36.0 \%$ & 39,167 & $4.6 \%$ & $-34,069$ & $-12.8 \%$ & $-4,203$ & $-60.8 \%$ & 0 & - \\
\hline Gabon & $-173,079$ & $-94.9 \%$ & 168,918 & $209.6 \%$ & 4,161 & - & 0 & - & 0 & - \\
\hline Ghana & 0 & $0.0 \%$ & 88,074 & $924.9 \%$ & $-44,340$ & $-23.9 \%$ & $-43,734$ & $-97.8 \%$ & 0 & - \\
\hline Guinea & 14,326 & $578.3 \%$ & $-8,996$ & $-3.8 \%$ & $-5,329$ & $-100.0 \%$ & 0 & - & 0 & - \\
\hline Guinea-Bissau & 0 & $0.0 \%$ & 0 & $0.0 \%$ & 0 & - & 0 & - & 0 & - \\
\hline Kenya & -473 & $-16.7 \%$ & $-57,755$ & $-18.7 \%$ & 14,451 & $6.9 \%$ & 42,727 & $67.0 \%$ & 1,050 & - \\
\hline Lesotho & $-30,673$ & $-99.6 \%$ & 29,680 & - & 886 & - & 107 & - & 0 & - \\
\hline Liberia & 3,185 & $134.7 \%$ & $-3,185$ & $-3.4 \%$ & 0 & - & 0 & - & 0 & - \\
\hline Libya & $-1,939$ & $-0.1 \%$ & 1,939 & $1.1 \%$ & 0 & - & 0 & - & 0 & - \\
\hline Madagascar & $-1,136$ & $-11.7 \%$ & 25,540 & $7.5 \%$ & -259 & $-0.2 \%$ & $-24,145$ & $-32.1 \%$ & 0 & - \\
\hline Malawi & 0 & - & 3,776 & $3.3 \%$ & $-3,776$ & $-85.0 \%$ & 0 & - & 0 & - \\
\hline Mali & $-14,680$ & $-40.2 \%$ & $-33,192$ & $-4.9 \%$ & 54,212 & $10.0 \%$ & $-6,340$ & $-100.0 \%$ & 0 & - \\
\hline Mauritania & $-5,726$ & $-3.7 \%$ & $-52,690$ & $-8.1 \%$ & 44,558 & $19.1 \%$ & 13,859 & - & 0 & - \\
\hline Morocco & $-120,135$ & $-29.6 \%$ & 120,135 & - & 0 & - & 0 & - & 0 & - \\
\hline Mozambique & -92 & $-2.6 \%$ & 22,738 & $7.2 \%$ & 25,351 & $7.9 \%$ & $-47,997$ & $-31.0 \%$ & 0 & - \\
\hline Namibia & $-91,301$ & $-46.7 \%$ & $-37,157$ & $-13.9 \%$ & 25,803 & $11.1 \%$ & 102,655 & $78.4 \%$ & 0 & - \\
\hline Niger & $-7,106$ & $-71.4 \%$ & $-59,912$ & $-8.2 \%$ & 89,908 & $21.4 \%$ & $-22,890$ & $-100.0 \%$ & 0 & - \\
\hline Nigeria & 12,720 & $207.2 \%$ & 211,503 & $66.7 \%$ & $-224,224$ & $-38.0 \%$ & 0 & - & 0 & - \\
\hline Rwanda & 1 & $31.9 \%$ & 109 & $0.4 \%$ & -109 & $-100.0 \%$ & 0 & - & 0 & - \\
\hline Sao Tome \& Principe & -542 & $-76.5 \%$ & 542 & - & 0 & - & 0 & - & 0 & - \\
\hline Senegal & 0 & $0.0 \%$ & 29,424 & $50.6 \%$ & $-29,424$ & $-21.2 \%$ & 0 & - & 0 & - \\
\hline Seychelles & 0 & $0.0 \%$ & 0 & - & 0 & - & 0 & - & 0 & - \\
\hline Sierra Leone & 12,880 & $332.4 \%$ & $-12,880$ & $-18.6 \%$ & 0 & - & 0 & - & 0 & - \\
\hline Somalia & $-6,118$ & $-61.2 \%$ & $-221,150$ & $-44.6 \%$ & 175,783 & $201.9 \%$ & 51,485 & $115.5 \%$ & 0 & - \\
\hline South Africa & $-592,894$ & $-64.9 \%$ & 416,362 & $159.6 \%$ & 86,292 & $251.3 \%$ & 90,240 & $767.6 \%$ & 0 & - \\
\hline
\end{tabular}


Table 4 Absolute change in areas $\left(\mathbf{k m}^{2}\right)$ for An. arabiensis per African country under scenario 2 (Continued)

\begin{tabular}{lcccccccccc}
\hline Sudan & $-1,929$ & $-1.6 \%$ & 166,575 & $20.4 \%$ & 30,088 & $2.4 \%$ & $-194,734$ & $-61.4 \%$ & 0 & - \\
Swaziland & -27 & $-33.3 \%$ & $-2,713$ & $-33.2 \%$ & $-3,715$ & $-45.3 \%$ & 6,455 & $1663.2 \%$ & 0 & - \\
Tanzania & 459 & $12.6 \%$ & 65,642 & $10.8 \%$ & $-1,941$ & $-1.0 \%$ & $-64,160$ & $-49.5 \%$ & 0 & - \\
The Gambia & 0 & $0.0 \%$ & 3,233 & $49.3 \%$ & $-3,233$ & $-100.0 \%$ & 0 & - & 0 & - \\
Togo & 0 & $0.0 \%$ & 45,722 & - & $-42,690$ & $-80.4 \%$ & $-3,032$ & $-100.0 \%$ & 0 & - \\
Tunisia & 0 & $0.0 \%$ & 0 & - & 0 & - & 0 & - & 0 & - \\
Uganda & 280 & $149.7 \%$ & 68,589 & $43.6 \%$ & $-59,762$ & $-75.7 \%$ & $-9,107$ & $-99.6 \%$ & 0 & - \\
Western Sahara & $-7,146$ & $-6.1 \%$ & 7,146 & $4.7 \%$ & 0 & - & 0 & - & 0 & - \\
Zambia & -900 & $-100.0 \%$ & 31,898 & $5.1 \%$ & $-30,998$ & $-25.4 \%$ & 0 & - & 0 & - \\
Zimbabwe & $-5,439$ & $-93.9 \%$ & $-11,414$ & $-5.2 \%$ & $-5,354$ & $-3.8 \%$ & 22,207 & $87.9 \%$ & 0 & - \\
Grand total & $-\mathbf{1 , 5 1 5 , 4 9 1}$ & $-\mathbf{2 0 . 2} \%$ & $\mathbf{1 , 6 7 0 , 8 2 3}$ & $\mathbf{1 2 . 0} \%$ & $-\mathbf{4 0 5 , 5 2 2}$ & $-\mathbf{5 . 5} \%$ & $\mathbf{2 4 9 , 1 4 1}$ & $\mathbf{2 1 . 5 \%}$ & $\mathbf{1 , 0 5 0}$ & -
\end{tabular}

Values were obtained by subtracting the Eco-climatic index (EI) estimates for future A. arabiensisdistribution from projected scenario 2 criteria to the $E /$ estimates obtained under current climate for each country. The percentages (\%) were calculated by dividing each absolute area change to the current area value per country. Tables 1, 2, 3, 4: (--) Represents the absolute change within a scale range in which the current value of area was zero (0); (+) indicates an increase; $(-)$ indicates a reduction in areas; (0) means no change.

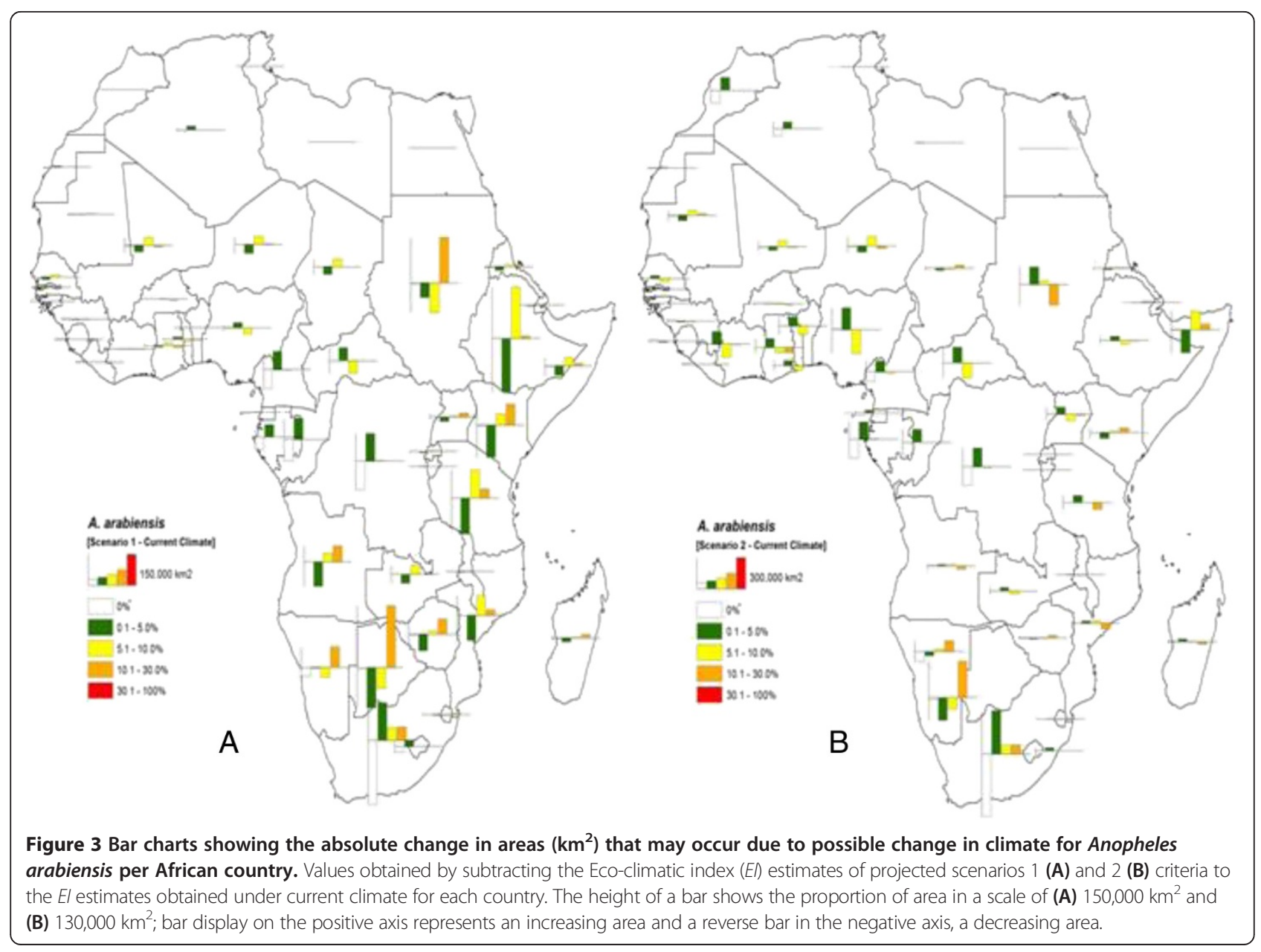


training needs may be regularly organized with emphasis on enhancing awareness, stimulating acceptance and active participation of the communities.

\section{Conclusion}

This paper estimates in $\mathrm{Km}^{2}$ and for each African country the absolute change in zone of suitability of the major malaria vectors, An. gambiae and An. arabiensis, under different projected climate scenarios. The potential shifts will have implications for the overall number of people exposed to the malaria vectors and the recrudescence of malaria is likely to be recorded in several new areas and regions. Based on the results, there is a need for developing, compiling and sharing malaria preventive measures, which can be adapted to different climatic scenarios.

\section{Competing interests}

The authors declare that they have no competing interests.

\section{Authors' contributions}

Conceived and designed the experiments: HEZT. Analyzed the data: HEZT HSJ. Wrote the paper: HEZT DPT HSJ LK IRFD. All authors approved the final version of the manuscript for submission.

\section{Acknowledgements}

The work is partly an outcome of the first round of the African Climate Change Fellowship Programme (ACCFP). The ACCFP was supported by a grant from the Climate Change Adaptation in Africa (CCAA), funded jointly by the International Development Research Centre (IDRC) of Canada and the UK's Department of International Development (DFID). The International START Secretariat was the implementing agency in collaboration with the Institute of Resource Assessment (IRA) of the University of Dar es Salaam and the African Academy of Sciences (AAS). The authors express their gratitude to Kalumanga Elikana and Madaka Tumbo for their suggestions during the initiation of this work.

\section{Author details}

IInternational Centre of Insect Physiology and Ecology (icipe), Nairobi, Kenya. ${ }^{2}$ Agrosanidad SAC / Archana EIRL, Jerez Q-8 Mayorazgo III Etapa, Lima 03, Peru. ${ }^{3}$ International Institute of Tropical Agriculture (IITA), Cotonou, Benin.

Received: 3 February 2014 Accepted: 27 April 2014

Published: 7 May 2014

\section{References}

1. Patz JA, Khaliq M: Global climate change and health: challenges for future practitioners. JAMA 2002, 287:2283-2284.

2. McMichael AJ, Woodruff RE, Hales S: Climate change and human health: present and future risks. Lancet 2006, 367:859-869.

3. Githeko AK, Lindsay SW, Confalonieri UE, Patz JA: Climate change and vector-borne diseases: a regional analysis. Bull World Health Organ 2000, 78:1136-1147.

4. Sutherst RW: Global change and human vulnerability to vector-borne diseases. Clin Microbiol Rev 2004, 17:136-173.

5. Reiter P: Climate change and mosquito-borne disease: knowing the horse before hitching the cart. Rev sci tech Off int Epiz 2008, 27(2):383-398.

6. Peterson AT: Shifting suitability for malaria vectors across Africa with warming Climates. BMC Infect Dis 2009, 9:59.

7. Stockwell DRB, Peters DP: The GARP modelling system: Problems and solutions to automated spatial prediction. Int J Geogr Inf Sci 1999, 13:143-158,

8. Lafferty K: The ecology of climate change and infectious diseases. Ecology 2009, 90:888-900.

9. Lindsay SW, Parson L, Thomas CJ: Mapping the ranges and relative abundance of the two principal African malaria vectors, Anopheles gambiae sensu stricto and An. arabiensis, using climate data. Lond Ser B-Biol Sci 1998, 265:847-854.

10. Smith DL, McKenzie FE: Statics and dynamics of malaria infection in Anopheles mosquitoes. Malaria J 2004, 3:13.
11. Levine RS, Peterson AT, Benedict MQ: Geographic and ecologic distributions of the Anopheles gambiae complex predicted using a genetic algorithm. Am J Trop Med Hyg 2004, 70:105-109.

12. Pascual M, Ahumada JA, Chabes LF, Rodo X, Bouma M: Malaria resurgence in the East African highlands: temperature trends revisited. Proc Natl Acad Sci U S A 2006, 103:5829-5834.

13. Dillon ME, Wang G, Huey RB: Global metabolic impacts of recent climate warming. Nature 2010, 467:704-706.

14. Tonnang ZEH, Kangalawe YMR, Yanda ZP: Predicting and mapping malaria under climate change scenarios: the potential redistribution of malaria vectors in Africa. Malaria J 2010, 9:111.

15. Martens WJ, Niessen LW, Rotmans J, Jetten TH, McMichael AJ: Potential impact of global climate change on malaria risk. Environ Health Persp 1995, 103:458-464.

16. van Lieshout M, Kovats RS, Livermore MTJ, Martens P: Climate change and malaria: analysis of the SRES climate and socio-economic scenarios. Global Environ Chang 2004, 14:87-99.

17. Ermert $\mathrm{V}$, Fink AH, Morse AP, Paeth $\mathrm{H}$ : The impact of regional climate change on malaria risk due to greenhouse forcing and land-use changes in tropical Africa. Environ Health Perspect 2012, 120:77-84.

18. Tanser FC, Sharp B, le Sueur D: Potential effect of climate change on malaria transmission in Africa. Lancet 2003, 362:1792-1798.

19. Bouma MJ, Baeza A, terVeen A, Pascual M: Global malaria maps and climate change: a focus on East African highlands. Trends Parasitol 2011, 27(10):421-422.

20. Mapping Malaria Risk in Africa. 2010, [http://www.mara.org.za/]

21. Koum G, Yekel A, Ndifon B, Simard F: Design and implementation of a mosquito database through an entomological ontology. Bioinform 2005, 21:2797-2802.

22. Moffett A, Strutz S, Guda N, González C, Ferro MC, Cordero VS, Sarkar S: A global public database of disease vector and reservoir distributions. PLoS Negl Trop Dis 2009, 3:3.

23. Sutherst RW, Maywald GF: A computerised system for matching climates in ecology. Agric Ecosyst Environ 1985, 13:281-299.

24. Intergovernmental Panel on Climate Chang (IPCC): In Climate Change: The Scientific Basis. Contribution of Working Group I to the Third Assessment Report of the Intergovernmental Panel on Climate Change. Edited by Houghton JT, Ding Y, Griggs DJ, Noguer M, van der Linden PJ, Dai X, Maskell K, Johnson CA. Cambridge, United Kingdom and New York, NY, USA: Cambridge University Press; 2001:881.

25. Roshan JV, Kang L: Regression-based inverse distance weighting with applications to computer experiments. Technometrics 2011, 53(3):254-265.

26. Thomas CJ, Davies G, Dunn CE: Mixed picture for changes in stable malaria distribution with future climate in Africa. Trends Parasitol 2004, 20:216-220.

27. Coluzzi M, Sabatini A, Petrarca V, di Deco MA: Chromosomal differentiation and adaptation to human environments in the Anopheles gambiae complex. T Roy Soc Trop Med H 1979, 73:483-497.

28. Touré YT, Petrarca V, Traoré SF, Coulibaly A, Maiga HM, Sankaré O, Sow M, Di Deco MA, Coluzzi M: The distribution and inversion polymorphism of chromosomally recognized taxa of the Anopheles gambiae complex in Mali, West Africa. Parassitologia 1998, 40:477-511.

29. Bayoh MN, Mathias DK, Odiere MR, Mutuku FM, Kamau L, Gimnig JE, Vulule JM, Hawley WA, Hamel MJ, Walker ED: Anopheles gambiae: historical population decline associated with regional distribution of insecticide-treated bed nets in western Nyanza Province, Kenya. Malaria J 2010, 9:62.

30. Russell TL, Lwetoijera DW, Maliti D, Chipwaza B, Kihonda J, Charlwood JD, Smith TA, Lengeler C, Mwanyangala MA, Nathan R, Knols BG, Takken W, Killeen GF: Impact of promoting longer-lasting insecticide treatment of bed nets upon malaria transmission in a rural Tanzanian setting with pre-existing high coverage of untreated nets. Malaria J 2010, 9:187.

31. World Health Organization: Mathematical Modelling to Support Malaria Control and Elimination. Roll Back Malar Prog Impact Ser 2010, 5:1-48.

32. African Press Organization: Science, technology, innovation and capacity building for addressing climate change. Issues Pap 2010, 10:1-10.

33. Lambin EF, Tran A, Vanwambeke SO, Linard C, Soti V: Pathogenic landscapes: interactions between land, people, disease vectors, and their animal hosts. Int J Health Geogr 2010, 9:54.

34. Foley DH, Wilkerson RC, Birney I, Harrison S, Christensen J, Christensen J, Rueda LM: MosquitoMap and the Mal-area calculator: new web tools to relate mosquito species distribution with vector borne disease. Int J Health Geogr 2010, 9:11. 
35. Linard C, Tatem AJ: Large-scale spatial population databases in infectious disease research. Int I Health Geogr 2012, 11:7.

36. Dambach P, Machault P, Lacaux JP, Vignolles C, Sié A, Sauerborn R:

Utilization of combined remote sensing techniques to detect environmental variables influencing malaria vector densities in rural West Africa. Int J Health Geogr 2012, 11:8.

doi:10.1186/1476-072X-13-12

Cite this article as: Tonnang et al:: Zoom in at African country level: potential climate induced changes in areas of suitability for survival of malaria vectors. International Journal of Health Geographics 2014 13:12.

\section{Submit your next manuscript to BioMed Central and take full advantage of:}

- Convenient online submission

- Thorough peer review

- No space constraints or color figure charges

- Immediate publication on acceptance

- Inclusion in PubMed, CAS, Scopus and Google Scholar

- Research which is freely available for redistribution 